\title{
Study on Urban Landscape Green Space - - A Case Study of Longquanshan Park
}

\author{
Huan Dai ${ }^{1, *}$, Wei $\mathrm{Li}^{1}$, Yan Zeng ${ }^{1}$ and Xinyang Zhang ${ }^{1}$ \\ ${ }^{1}$ Wuhan Institute of Design and Sciences, Wuhan 430205, China
}

\begin{abstract}
Studying on Qinglongshan Forest Park in Wuhan by typical plot method, 15 typical plots in the park were investigated, and the species richness index, diversity index, evenness index, frequency and important value index were calculated. The results showed that there were 139 species of woody plants belonging to 46 families and 97 genera, including 41 species of evergreen trees, 32 species of deciduous trees, 62 species of evergreen shrubs, 25 species of deciduous shrubs, and 4 species of bamboo belonging to 1 family, 3 genera. Species richness index and Simpson diversity index were all expressed as tree layer $>$ shrub layer, evergreen species $>$ deciduous species. Pielou evenness was tree layer $>$ shrub layer. This study can provide some reference for understanding the existing plant status of forest parks, carrying out science popularization, scientific research, protection and improvement of forest landscape quality.
\end{abstract}

\section{Introduction}

Urban green space is an important part of urban landscape, it can not only play its aesthetic function, but also reduce thermal radiation and adjust temperature and humidity [1]. There is great social value for improving the environmental protection of urban residents and raising their awareness of environmental protection. It plays an important role in improving the urban environment and urban sustainable development. It is also an important indicator of the overall environmental level of the city and the quality of life of residents [2].

Woody plants in urban forest parks not only have important ecological functions in improving the environment and improving the image of the city, but also plays an important role in creating urban forest landscape and maintaining the stability of the ecosystem. However, most of the plant landscapes in urban parks are artificial plant communities. There is great manual intervention in urban forest parks, and the plant communities in the park are often fragile and poorly self-healing [3]. Therefore, the study of plant community structure and woody plant diversity in urban forest parks is of great significance to the construction of urban ecological environment and sustainable development.

\section{Resarch area and method}

\subsection{Overview of the research area}

Wuhan is located in the inland of central China and belongs to the subtropical monsoon humid climate zone. At the same time, it has abundant rainfall, sufficient sunshine, distinct seasons, high temperature in summer, concentrated precipitation, and cold in winter. The annual average temperature is $16^{\circ} \mathrm{C}-18^{\circ} \mathrm{C}$ for many years, and the average temperature from December to January is the lowest, $1.2^{\circ} \mathrm{C}$. The highest average temperature was $30{ }^{\circ} \mathrm{C}$ in July, August and September. Summer is very long, lasting from mid-May to late October, up to 130 days [4].

Qinglongshan Forest Park is located in the southeast street of Zhifang, Chengguan Town, Jiangxia District, Wuhan City. It was built in 1989 with Xiongtingbi Park and other attractions. The park is a comprehensive park with humanistic landscape. The park architecture is based on the natural scenery of the forest. The humanistic architecture adopts the classical architectural style of the Ming Dynasty, the eaves arch wall, the simple and elegant, the landscape in the park is beautiful, the pavilion is jade, and the flowers and trees are magnificent.

\subsection{Investigation method}

The typical sampling method in sample plot method was adopted. Based on comprehensive investigation, the mountainous forest area in Qinglongshan Forest Park was selected. The sample plots were set up according to the representative mountainous forest with relatively abundant species and light disturbance. Fifteen sample plots were sampled, and each sample plot was $30 \mathrm{~m} \times 30$ $\mathrm{m}$. The tree species, number, $\mathrm{DBH}$, crown width, tree height and growth status in the sample plots were recorded respectively. Five $5 \mathrm{~m} \times 5 \mathrm{~m}$ quadrats were set in each quadrat to investigate the shrub layer data, and 5 recorded the shrub species name, plant height, plant number and growth status. Five $5 \mathrm{~m} \times 5 \mathrm{~m}$ plots were set in each plot to investigate the herb layer data, and the species name,

\footnotetext{
* Corresponding author: 191735729@qq.com
} 
frequency and growth status of woody plant seedlings were counted.

\subsection{Data processing}

\subsubsection{Calculation of species importance}

- Important values $=$ (relative density + relative frequency + relative coverage) $/ 3$

- Important value of herb $=$ (elative coverage + relative frequency) / 2

- $\quad$ Relative density $=$ (number of individuals of several individuals of all species $) \times 100 \%$

- Relative frequency $=$ (frequency of a species / frequency sum of all species) $\times 100 \%$

- Relative coverage $=($ coverage of a species $/$ total coverage of all species) $\times 100 \%$

\subsubsection{Species diversity calculation}

- Shannon-Wiener diversity index: $\mathrm{H}=-\sum \mathrm{PilnPi}$

- Simpson diversity index: $\mathrm{D}=1-\sum \mathrm{Pi}^{2}$

- Pielou diversity index: $E=H / \ln S$

- Margalef richness index: $\mathrm{R}=(\mathrm{S}-1) / \mathrm{lnN}$

In the formula $\mathrm{N}$ : $\mathrm{Pi}=\mathrm{Ni} / \mathrm{N}$; $\mathrm{Ni}-$ Number of individuals of $\mathrm{Ni}-\mathrm{I}$ species;

$\mathrm{N}$ - Total number of individuals of all species; $\mathrm{S}-$ Number of all plant species in the plotv.

\section{Results and analysis}

\subsection{Formatting the title}

The result showed that there were 139 species of woody plants were investigated, belonging to 46 families and 97 genera. There were 41 evergreen trees and 32 deciduous trees, accounting for $52.51 \%$ of the total plant species. Pinus massoniana, Cunninghamia lanceolata, Cryptomeria fortunei, cypress funebris, Cinnamomum camphora, Liquidambar formosana and Magnolia officinalis were the most frequently used trees. There are 37 kinds of evergreen shrubs and 25 kinds of deciduous shrubs, accounting for $44.60 \%$ of the total number of plants. The shrubs with high frequency of application are Loropetalum chinense, Lindera glauca, Halodendron chinense, Platycladus orientalis and Elaeagnus angustifolia. There are 4 kinds of bamboo, of which the highest frequency of application is Phyllostachys heterocycla and Phyllostachys sulphurea var. viridis.

Dominant family's analysis showed that, there are 3 genera 4 species in Pinaceae, 5 genera 9 species in Fagaceae, 9 genera 14 species in Rosaceae, 3 genera 4 species in Hamamelidaceae, 7 genera 9 species in Leguminosae, and 4 genera 5 species in Lauraceae. The top two dominant families were Rosaceae and Leguminosae, with 14 species of 9 genera in Rosaceae accounting for $10.07 \%$ of the total plant species, and 9 species of 7 genera in Leguminosae accounting for $6.47 \%$ of the total plant species.

\subsection{Frequency analysis}

Frequency refers to the occurrence rate of individual plants in specific plots in a certain area. It not only reflects the density of each plant in the community, but also reflects the distribution of plant species in the community [5]. The maximum frequency of Pinus massoniana in tree layer was $85.24 \%$. The frequency of Liquidambar formosana, Cunninghamia lanceolata, Broussonetia papyrifera and Cinnamomum camphora were more than $50 \%, 71.36 \%, 52.41 \%, 51.63 \%$ and $66.37 \%$, respectively. The frequency of Loropetalum chinense var. rubrum disc in shrub layer was the highest, $82.35 \%$. The frequency of Halodendron chinense var. rubrum, Rosa laevigata and Lonicera japonica were $71.65 \%, 63.24 \%$ and $56.78 \%$, respectively.

The tree species with higher tree layer frequency are Pinus massoniana, Liquidambar formosana and Cinnamomum camphora, the frequency is above $60 \%$, and the frequency of Cunninghamia lanceolata and Broussonetia papyrifera is above $50 \%$. There are 27 species of plants with frequency less than $50 \%$ were found, accounting for $36.98 \%$ of all tree layer plants. The tree species with the highest frequency in shrub layer were Loropetalum chinense, Ilex holly, Rosa laevigata, and Haloxylon amabilis, with the frequency above $50 \%$. The remaining 36 shrub species did not reach $60 \%$, accounting for $58.06 \%$ of all shrub species. The highest occurrence frequency of woody plant seedlings was Liquidambar formosana and Ilex chinensis, which were $70.34 \%$ and $61.74 \%$, respectively.

\subsection{Important value analysis}

Important value represents a comprehensive quantitative indicator of the status and role of a species in a population, reflecting its dominance [6]. A total of 139 species belonging to 97 genera and 46 families were recorded, including 73 species belonging to 53 genera and 26 families in tree layer, 62 species belonging to 41 genera and 19 families in shrub layer and 4 species belonging to 3 genera and 1 family in bamboo. As shown in Table 1 , the species with the highest importance value in the tree layer were Pinus massoniana, Liquidambar formosana, Cinnamomum camphorabar formosana, Cinnamomum camphora and Cunninghamia lanceolata. As shown in Table2, the relative density of Pinus massoniana is the highest, which is 0.5447 . The most important species in shrub layer were Loropetalum chinense var. rubrum, Rosa laevigata, Rhus chinensis, Serissa japonica and Camellia oleiferal, Loropetalum chinense var. rubrum had the highest relative density, which is 0.6160 . The species with the highest important values of woody plants in the herb layer were Liquidambar formosana, Ilex holly, Quercus glandulifera, Loropetalum chinense and Quercus glauca, as shown in Table3. 
Table1. List of important values of tree layer plants

\begin{tabular}{|c|c|c|c|c|}
\hline Serial numbe & Species & Relative density & Relative cover & Importance value \\
\hline 1 & Pinus massomiana & 0.5447 & 0.7923 & 0.7585 \\
\hline 2 & Liquidambar & 0.5395 & 0.6538 & 0.8082 \\
\hline 3 & Cinnamomum camphora & 0.2855 & 0.5769 & 0.7261 \\
\hline 4 & Cunninghamia lanceolata & 0.3283 & 0.4385 & 0.6552 \\
\hline 5 & Cupressus funebris & 0.1125 & 0.3295 & 0.5323 \\
\hline 6 & Broussonetia papyrifera & 0.4769 & 0.6519 & 0.6957 \\
\hline \multicolumn{5}{|c|}{ Table2. List of important values of shrub layer plants } \\
\hline Serial numbe & Species & Relative density & Relative cover & Importance value \\
\hline 1 & $\begin{array}{l}\text { Loropetalum chinense var. } \\
\text { rubrum }\end{array}$ & $\begin{array}{l}0.6160 \text { shrub } \\
\text { layer }\end{array}$ & 0.7092 & 0.8251 \\
\hline 2 & Rosa laevigata & 0.5681 & 0.6123 & 0.6503 \\
\hline 3 & Ilex chinensis & 0.3614 & 0.5967 & 0.7315 \\
\hline 4 & Rhus chinensis & 0.2528 & 0.3858 & 0.5124 \\
\hline 5 & Serissa japonica & 0.2983 & 0.4267 & 0.6983 \\
\hline 6 & Camellia oleiferal & 0.3767 & 0.3523 & 0.5862 \\
\hline \multicolumn{5}{|c|}{ Table3. List of important values of herbaceous layer plants } \\
\hline Serial numbe & Species & Relative density & Relative cover & Importance value \\
\hline 1 & Liquidambar formosana & 0.6352 & 0.3556 & 0.8338 \\
\hline 2 & Loropetalum chinense & 0.4513 & 0.5422 & 0.5975 \\
\hline 3 & Ilex chinensis & 0.3865 & 0.1937 & 0.6214 \\
\hline 4 & Serissa japonica & 0.2926 & 0.2103 & 0.4317 \\
\hline 5 & Rosa multiflora & 0.5328 & 0.4017 & 0.6828 \\
\hline 6 & Rosa laevigata & 0.4729 & 0.2033 & 0.5923 \\
\hline
\end{tabular}

\subsection{Species richness analysis}

Species richness is used to reflect the distribution frequency of species number in a certain spatial range. The mean Margalef species richness index of tree layer is 1.3134. The mean Margalef species richness index of shrub layer is 0.2045 . The top five tree layer richness in Table 2-9 were plot 2 (2.4146), plot 1 (2.0377), plot 4 (1.9494), plot 14 (1.5417) and plot 8 (1.5005). The top five shrub species richness in Table4 were plot 4 (0.9540), plot $12(0.6710)$, plot $5(0.3593)$, plot $13(0.2872)$ and plot 9 (0.1699).

Table4. List of species richness index

\begin{tabular}{|c|c|c|c|c|c|c|c|}
\hline $\begin{array}{c}\text { Plot } \\
\text { number }\end{array}$ & $\begin{array}{l}\text { Tree } \\
\text { layer }\end{array}$ & $\begin{array}{l}\text { Shrub } \\
\text { layer }\end{array}$ & $\begin{array}{l}\text { Herbaceous } \\
\text { layer }\end{array}$ & $\begin{array}{c}\text { Plot } \\
\text { number }\end{array}$ & $\begin{array}{l}\text { Tree } \\
\text { layer }\end{array}$ & $\begin{array}{l}\text { Shrub } \\
\text { layer }\end{array}$ & $\begin{array}{l}\text { Herbaceous } \\
\text { layer }\end{array}$ \\
\hline 1 & 2.0377 & 0.1314 & 1.8312 & 9 & 0.9618 & 0.1699 & ---- \\
\hline 2 & 2.4146 & 0.1257 & 1.8632 & 10 & 0.8820 & 0.0202 & 0.8762 \\
\hline 3 & 1.3138 & 0.0250 & 0.9125 & 11 & 0.3338 & 0.3231 & ---- \\
\hline 4 & 1.9494 & 0.9540 & 0.9315 & 12 & 1.2427 & 01510 & ---- \\
\hline 5 & 1.2325 & 0.3593 & & 13 & 1.1343 & 0.2872 & 0.8735 \\
\hline 6 & 1.3231 & 0.0005 & 0.6967 & 14 & 1.5417 & 0.1210 & 1.2536 \\
\hline 7 & 0.9854 & 0.1245 & & 15 & 0.5139 & 0.1415 & ---- \\
\hline 8 & 1.5005 & 0.1241 & 1.3153 & & & & \\
\hline
\end{tabular}

\subsection{Species diversity index analysis}

Species diversity is an important index to measure the complexity of community structure and function. The plant species diversity index is large, indicating that the plant community type in the region is composed of multiple tree species, abundant species and complex structure [7]. Shannon-Winner index is more stable to reflect community diversity because it is not affected by sample size. Shannon-Winner index is used to reflect species richness in communities[8]. According to Table5, the top five plots of Shannon-Winner index in arbor layer were plot 2 (2.9331), plot 6 (2.8215), plot 8 (2.7531), plot 4 (2.6878), and plot 1 (2.5947), respectively. The top five plots of Shannon-Winner index in shrub layer were plot 13 (1.9832), plot 5 (1.9421), plot 15 (1.9322), plot 1 (1.9157), and plot 9 (1.9028), respectively. 
Table5. List of Shannon-Winner index

\begin{tabular}{cllllllll}
\hline $\begin{array}{c}\text { Plot } \\
\text { number }\end{array}$ & $\begin{array}{l}\text { Tree } \\
\text { layer }\end{array}$ & $\begin{array}{l}\text { Shrub } \\
\text { layer }\end{array}$ & $\begin{array}{l}\text { Herbaceous } \\
\text { layer }\end{array}$ & & $\begin{array}{c}\text { Plot } \\
\text { number }\end{array}$ & $\begin{array}{l}\text { Tree } \\
\text { layer }\end{array}$ & $\begin{array}{l}\text { Shrub } \\
\text { layer }\end{array}$ & $\begin{array}{l}\text { Herbaceous } \\
\text { layer }\end{array}$ \\
\hline 1 & 2.5947 & 1.9157 & 0.5421 & & 9 & 2.5231 & 1.9028 & ---- \\
2 & 2.9331 & 1.2186 & 0.6325 & & 10 & 2.3026 & 1.6412 & 0.7651 \\
3 & 2.3897 & 1.1214 & 0.6747 & & 11 & 1.9550 & 1.6218 & ---- \\
4 & 2.6878 & 1.6308 & 0.9821 & & 12 & 2.1250 & 1.8982 & --- \\
5 & 2.4100 & 1.9421 & & 13 & 1.9743 & 1.9832 & 1.0105 \\
6 & 2.8215 & 1.6323 & 0.5323 & & 14 & 2.5312 & 1.8230 & 0.6528 \\
7 & 2.2897 & 1.5773 & & 15 & 1.9549 & 1.9322 & ---- \\
8 & 2.7531 & 0.5115 & 0.9646 & & & & & \\
\hline
\end{tabular}

Simpson diversity index is used to reflect the probability of two plant individuals belonging to the same species in the community. According to Table 6, the top five plots of Simpson diversity index in tree layer are plot 2 (0.9351), plot 4 (0.9322), plot 12 (0.9250), plot 1
(0.8819), and plot 13 (0.8143), respectively. The first five plots of Simpson diversity index in shrub layer were plot $5(0.8614)$, plot $13(0.8523)$, plot $1(0.8321)$, plot 9 (0.7712), and plot 4 (0.7631), respectively.

Table6. List of Simpson index

\begin{tabular}{|c|c|c|c|c|c|c|c|}
\hline $\begin{array}{c}\text { Plot } \\
\text { number }\end{array}$ & $\begin{array}{l}\text { Tree } \\
\text { layer }\end{array}$ & $\begin{array}{l}\text { Shrub } \\
\text { layer }\end{array}$ & $\begin{array}{l}\text { Herbaceous } \\
\text { layer }\end{array}$ & $\begin{array}{c}\text { Plot } \\
\text { number }\end{array}$ & $\begin{array}{l}\text { Tree } \\
\text { layer }\end{array}$ & $\begin{array}{l}\text { Shrub } \\
\text { layer }\end{array}$ & $\begin{array}{l}\text { Herbaceous } \\
\text { layer }\end{array}$ \\
\hline 1 & 0.8819 & 0.8321 & 0.2125 & 9 & 0.7938 & 0.7712 & --- \\
\hline 2 & 0.9351 & 0.6022 & 0.2653 & 10 & 0.7822 & 0.7621 & 0.3213 \\
\hline 3 & 0.8003 & 0.6231 & 0.2124 & 11 & 0.8140 & 0.5216 & ---- \\
\hline 4 & 0.9322 & 0.7631 & 0.3102 & 12 & 0.9250 & 0.7577 & ---- \\
\hline 5 & 0.7912 & 0.8614 & & 13 & 0.8143 & 0.8523 & 0.2023 \\
\hline 6 & 0.8113 & 0.7595 & 0.1215 & 14 & 0.8050 & 0.6256 & 0.0562 \\
\hline 7 & 0.8079 & 0.6887 & & 15 & 0.8123 & 0.4216 & ---- \\
\hline 8 & 0.8094 & 0.7132 & 0.1319 & & & & \\
\hline
\end{tabular}

\subsection{Analysis of species evenness}

Species evenness is a distribution of the number of individuals of all species in a community or habitat, reflecting the degree of uniformity in the distribution of individual species. According to table7, the top five plots of tree layer evenness were plot12 (0.5235), plot4 (0.5176), plot14 (0.4932), plot2 (0.4905), plot9 (0.4873). The top five plots of shrub layer evenness were plot 1 (0.4512), plot9 (0.3762), plot4 (0.3541), plot6 (0.3421), plot7 (0.3357).

Table7. List of species evenness

\begin{tabular}{clllcllll}
\hline $\begin{array}{c}\text { Plot } \\
\text { number }\end{array}$ & $\begin{array}{l}\text { Tree } \\
\text { layer }\end{array}$ & $\begin{array}{l}\text { Shrub } \\
\text { layer }\end{array}$ & $\begin{array}{l}\text { Herbaceous } \\
\text { layer }\end{array}$ & & $\begin{array}{c}\text { Plot } \\
\text { number }\end{array}$ & $\begin{array}{l}\text { Tree } \\
\text { layer }\end{array}$ & $\begin{array}{l}\text { Shrub } \\
\text { layer }\end{array}$ & $\begin{array}{l}\text { Herbaceous } \\
\text { layer }\end{array}$ \\
\hline 1 & 0.3246 & 0.4521 & 0.8062 & & 9 & 0.4873 & 0.3762 & ---- \\
2 & 0.4905 & 0.3124 & 0.6884 & & 10 & 0.3832 & 0.3152 & 1.1617 \\
3 & 0.4392 & 0.2321 & 0.4062 & & 11 & 0.4098 & 0.2421 & --- \\
4 & 0.5176 & 0.3541 & 0.7551 & & 12 & 0.5235 & 0.1594 & --- \\
5 & 0.4525 & 0.1566 & & 13 & 0.2756 & 0.2376 & 1.3105 \\
6 & 0.3521 & 0.3421 & 0.5608 & & 14 & 0.3532 & 0.3124 & 0.9281 \\
7 & 0.3137 & 0.3357 & & 15 & 0.2843 & 0.2415 & --- \\
8 & 0.3721 & 0.2541 & 1.2661 & & & & & \\
\hline
\end{tabular}

\section{Conclusions and discussion}

As an important part of urban green space ecosystem, the diversity of landscape plants is not only the standard to measure the level of urban greening, but also one of the important symbols of the level of urban greening. Native plants are the most stable part of the local ecosystem. Using native tree species can avoid the crisis of ecological balance broken by alien species. The existing coniferous forests are mainly Pinus massoniana forest, Chinese fir forest and cypress forest. In general, the vegetation growth is too dense. This kind of forest species is mainly protected, and human destruction, development and construction are strictly prohibited, so that it forms a good evergreen coniferous forest background in Qinglong Mountain Scenic Area. At present, there are many evergreen forests and foliage plants in the park. However, there are few deciduous forests, flowering plants and 
colored-leaf trees, and the landscape effect is poor. Therefore, according to the requirements of forest ecological environment and natural landscape, we must follow the principle of biodiversity, and scientifically and reasonably transform the vegetation community dominated by Pinus massoniana.

During the continuous process of Qinglong Mountain, the relatively flat area of the valley covered by the two mountains is the main tour route and an important landscape belt in the scenic area planning, and the natural environment is unique. In this section, the forest landscape dominated by color-leaf forests is planned to be formed, and color-leaf trees such as Liquidambar formosana, Magnolia grandiflora, Ginkgo biloba, Elaeocarpus sylvestris and Koelreuteria paniculata are planted. On the basis of the current vegetation, in the mode of natural community, the broad-leaved tree species, color-leaved tree species and flower shrubs with high ornamental value are arranged in pieces, and the key sections are combined with the main body of the scenic spots to configure plants, forming a multi-level and multi-species landscape forest composed of large trees, sub-trees, large shrubs, subshrubs, woody ground cover, grass ground cover and lawn, highlighting the characteristics of mountain forest wild interest, so that the prospect layer of the scenic area is dyed and the landscape effect of near-sight mountain flowers is romantic.

Based on adhering to the ecological science, considering the local characteristics of plants and the overall landscape expression effect, a plant landscape community with rich ornamental characteristics, highlighting the landscape effect and rich seasonal color changes is created to improve the landscape quality of the scenic area. The ornamental characteristics of rich and colorful plants, such as shape, color, fragrance and posture, are connected and closely combined with various landscape spaces in Qinglong Mountain area to form plant landscapes with obvious ecological effects and beautiful visual effects.

\section{Acknowledgments}

This research was financially supported by the Scientific Resarch Project of Wuhan Institute of Design and Sciences (K201915 and K201905), the Project of Excellent Course (201308), the Project of Teaching Research (2020JY104 and 2019JY111), and the Teaching Resarch Project of Hubei Provincal Universities (2018496 and 2017505).

\section{References}

1. Lijun Zhang 2018. (xinjiang: Shihezi University) P21-32

2. Juan Wang 2013. (Nanjing: Nanjing agricultural university) P23-66

3. Yingjia Tian and Long He 2018. (Chengdu: Sichuan Forest Prospecting Design) P46-51

4. Xiaoxue Cao, Jianwu Huang, Yi Jie 2014. (Nanchang: Acta Agriculturae Jiangxi) P 84-89+93
5. Kun Zhao, Jiangqiong Pan 2018. (Journal of Southwest Forestry University (Social Sciences)) P 87-91.

6. Pujie Wei, Bing Sun, Xinru He, Chang Liu, Shengke, Hu and Yongjun Fei 2019. (Journal of

Henan Normal University(Natural Science Edition)) P112-119.

7. Bo Chen, Lan Jiang, Ziyang Xie, Yangdi LI, Jiaxuan Li, Mengjia Li, Sichen Li, Cong Xing,

Jinfu Liu, Zhongsheng He 2021, (Biodiversity Science)P439-448.

8. Lifeng Yin, Wei Li, Binbin Ren2021. Journal of West China Forestry Science)P28-34. 